\title{
CARACTERIZAÇÃO FÍSICO-QUÍMICA DA MANGA 'TOMMY ATKINS' SUBMETIDA A APLICAÇÃO DE CLORETO DE CÁLCIO PRÉ-COLHEITA E ARMAZENAMENTO REFRIGERADO
}

\author{
Ana Veruska Cruz da Silva ${ }^{1,3^{*}}$; Josivan Barbosa Menezes² \\ ${ }^{1}$ Pós-Graduanda do Depto. de Produção Vegetal - FCAV/UNESP, Rod. Prof. Dr. Paulo Castellane, km 5 , \\ CEP: 14870-000 - Jaboticabal, SP. \\ 2Depto. de Química e Tecnologia - ESAM, CEP: 54870-000 - Mossoró, RN. \\ Bolsista CAPES. \\ *Autor correspondente <veruska@fcav.unesp.br>
}

\begin{abstract}
RESUMO: Avaliou-se a qualidade pós-colheita de manga 'Tommy Atkins' submetida a aplicação pré-colheita de $\mathrm{CaCl}_{2}$ e armazenamento refrigerado. Os fatores estudados foram concentrações de $\mathrm{CaCl}_{2}(1 \%$ e $2 \%)$ e números de aplicações (2,3 e 4 vezes). Houve ainda um tratamento adicional, que funcionou como controle. As pulverizações foliares foram iniciadas cerca de 35 dias após antese, num intervalo de 15 dias. Do total de 280 frutos colhidos, 175 foram levados para análise imediata, enquanto que 105 permaneceram em câmara fria $\left(10^{\circ} \mathrm{C}\right)$ por 30 dias, sendo posteriormente analisados. As concentrações de $\mathrm{CaCl}_{2}$ testadas não resultaram em incremento do teor de cálcio no fruto e também não influenciaram as características de qualidade avaliadas. Houve efeito do número de aplicações de $\mathrm{CaCl}_{2}$ sobre a textura, sólidos solúveis (após 30 dias) e açúcares solúveis totais (após a colheita). A incidência de colapso interno não foi associada a aplicação de cálcio.
\end{abstract}

Palavras-chave: Mangifera indica, cálcio, colapso interno

\section{PHYSICO - CHEMICAL CHARACTERIZATION OF THE ' TOMMY ATKINS' MANGO SUBMITTED TO PREHARVEST APPLICATION OF CALCIUM CHLORIDE AND REFRIGERATED STORAGE}

\begin{abstract}
The postharvest quality of 'Tommy Atkins' mango was evaluated after the preharvest application of $\mathrm{CaCl}_{2}$ and refrigerated storage. The studied factors were concentrations of $\mathrm{CaCl}_{2}(1 \%$ e $2 \%)$ and numbers of applications (2, 3 and 4 times). The spraying began 35 days after antese in intervals of 15 days. Of the 280 harvested fruits, 175 were taken for immediate analysis, while 105 , were left in a cold chamber $\left(10^{\circ} \mathrm{C}\right)$ during 30 days for later analysis. Significant difference was observed between the tested concentrations of $\mathrm{CaCl}_{2}$ and the witness, for most of the appraised quality characteristics, except for total sugars (fruits analyzed after 30 days), while the number of applications presented influence on the texture, soluble solids (after 30 days) and total soluble sugars (after the harvest).

Key words: Mangifera indica, calcium, internal breakdown
\end{abstract}

\section{INTRODUÇÃO}

A manga (Mangifera indica, L.) é um fruto tipicamente tropical, em franca expansão em nível mundial. O mercado potencial para exportação é muito exigente quanto a qualidade dos frutos. Observa-se uma ascensão mundial na demanda, ampliando as perspectivas para os países produtores. É notório a mudança nos hábitos alimentares dos povos desenvolvidos, em conseqüência do reconhecimento da necessidade de uma alimentação sadia.

O Rio Grande do Norte apresenta enorme potencial como produtor, consumidor e exportador de manga in natura e industrializada, devido às condições edafoclimáticas e localização privilegiada, ou seja, próximo aos mercados consumidores.

Como todos os frutos, a manga pode ter sua qualidade comprometida devido a diversos fatores como doenças, pragas e deficiências nutricionais, variando em função do cultivar, do grau de maturação e dos tratamentos utilizados na pré-colheita, colheita e pós-colheita. Os métodos empregados nas duas últimas fases (colheita e pós-colheita) retardam o processo de senescência, mas não alteram a qualidade do fruto. Os problemas póscolheita são comuns em manga, sendo o mais grave deles, o colapso interno (mundialmente conhecido como Internal breakdown) que, segundo Ferreira (1989), tem incidência, em alguns casos, de até $100 \%$.

O colapso interno resulta na perda de organização celular, e é caracterizado pela degradação da polpa. Sua ocorrência em manga ainda não é totalmente esclarecida. Esse problema tem ocasionado sérias perdas econômicas, principalmente por ser de difícil detecção, sendo na maioria das vezes detectado apenas pelo consumidor final. Esse fato vem despertando interesse de pesquisadores e, segundo Menezes (1997), a incidência dessa desordem está relacionada com baixos níveis de cálcio foliar, sugerindo-se portanto, que a aplicação de cálcio em pré- 
colheita da manga, seria uma alternativa viável à manutenção de sua qualidade. Porém, torna-se necessário verificar a eficiência da utilização, o número de pulverizações, as concentrações do produto e intervalo de aplicações exatos.

Diante do exposto, o objetivo do presente trabalho foi avaliar duas concentrações de cloreto de cálcio e diferentes números de aplicações, bem como a eficiência do produto quando aplicado em pré-colheita sobre a qualidade da manga 'Tommy Atkins'.

\section{MATERIAL E MÉTODOS}

O experimento foi desenvolvido em pomar comercial localizado no Pólo Agrícola Mossoró-Assú, RN, no período de setembro a dezembro de 1997. Esta região localiza-se a $5^{\circ} 13^{\prime}$ de latitude e $44^{\circ} 28^{\prime}$ de longitude oeste, com altitude de 15 metros acima do nível do mar. O clima é quente, seco e semi-árido, com precipitação anual média de $423 \mathrm{~mm}$, e temperatura máxima de $33^{\circ} \mathrm{C}$ e mínima de $29^{\circ} \mathrm{C}$. O solo é um Latossolo padronizado com textura arenosa, e a irrigação do pomar foi realizada por meio de microaspersão, variando o tempo de irrigação ( 0 a 7 horas) com o estádio de desenvolvimento do fruto. O pomar recebeu tratos culturais regulares de capina, tratamentos fitossanitários e adubações convencionais com N (7,2 $\left.\mathrm{kg} \mathrm{ha}^{-1}\right), \mathrm{P}\left(18 \mathrm{~kg} \mathrm{ha}^{-1}\right), \mathrm{K}\left(36 \mathrm{~kg} \mathrm{ha}^{-1}\right), \mathrm{Ca}\left(12,6 \mathrm{~kg} \mathrm{ha}^{-1}\right) \mathrm{e}$ $\mathrm{Mg}\left(7,2 \mathrm{~kg} \mathrm{ha}^{-1}\right)$, além de $12 \mathrm{~kg} \mathrm{ha}^{-1}$ de fertilizante composto de uma mistura contendo $70 \%$ de sulfato de zinco, $13 \%$ de ácido bórico e $17 \%$ de sulfato de cobre. As mangueiras selecionadas eram do cultivar Tommy Atkins, plantadas em espaçamento de $8,0 \times 6,0 \mathrm{~m}$, com 6 anos de idade.

$O$ delineamento experimental utilizado foi em blocos inteiramente casualizados, segundo um esquema de parcelas subdivididas, cujas parcelas foram dispostas em linhas com cinco repetições, havendo ainda um tratamento adicional, sem aplicação, que funcionou como controle. Nas parcelas, alocaram-se as concentrações de cloreto de cálcio ( $1 \%$ e $2 \%$ ), e nas subparcelas, o número de aplicações do produto (2, 3 e 4 vezes). As pulverizações foliares iniciaram-se quando o fruto encontrava-se no estádio "bola-de-gude", ou seja, \pm 35 dias após a antese, e foram realizadas a cada 15 dias, sempre no final da tarde, aproximadamente às 17:00h , por meio de atomizador.

Os frutos foram colhidos no estádio de maturação usualmente utilizado para exportação, caracterizado pelo enchimento da região proximal (ombros) em relação ao pedúnculo. Cada parcela experimental constou de 120 plantas, sendo 40 plantas por sub-parcela e 8 plantas por repetição. Colheram-se, aleatoriamente, 5 frutos por repetição, ou seja, 25 frutos por sub-parcela, perfazendo um total de 175 frutos. Ainda em campo, eles foram selecionados quanto aos defeitos e uniformidade de tamanho e coloração.

Imediatamente após a colheita e seleção, foram realizados os tratamentos fitossanitários pós-colheita utilizado para exportação, que consistiram na imersão dos frutos em um tanque contendo Procloraz, a $100 \mathrm{mg}$ de i.a. $L^{-1} e$ espalhante adesivo. Ao final desse processo, os frutos foram acondicionados em caixas de papelão utilizadas no mercado interno e levados para o Laboratório do Departamento de Química e Tecnologia da Escola Superior de Agricultura de Mossoró (ESAM), onde foram realizadas as análises físico-químicas.

Do total de 280 frutos colhidos, 105 destinaramse a um período de armazenamento, em câmara fria $\left(10^{\circ} \mathrm{C}\right)$ na empresa proprietária do pomar comercial por 30 dias após a colheita, sendo então posteriormente, levados ao laboratório da ESAM para a realização das análises.

No laboratório, fez-se a remoção da casca e a homogeneização da polpa em processador doméstico. Parte desta polpa preparada foi analisada imediatamente quanto aos teores de acidez total titulável (ATT) e sólidos solúveis (SS) e, outra parte, colocada em placas de Petri, previamente pesadas, embaladas em filmes de polietileno e mantidas a $-18^{\circ} \mathrm{C}$, sendo posteriormente liofilizadas para que se pudesse realizar as demais análises (açúcares solúveis totais e cálcio total).

A metodologia utilizada na determinação dos parâmetros selecionados para este estudo são descritos a seguir:

Textura: foi realizada somente nos frutos que foram submetidos ao armazenamento refrigerado por 30 dias. A textura foi determinada individualmente (duas determinações por fruto), utilizando-se um penetrômetro Mc Cormick modelo FT 327, em regiões equatoriais da superfície do fruto desprovido de uma pequena porção da casca. Os resultados obtidos em lb foram convertidos para Newtons (N), multiplicando-se os valores pelo fator 4,4482.

Incidência do Colapso Interno: foi avaliada em cada fruto, cortando-os longitudinalmente, de maneira a expor os tecidos para a avaliação do distúrbio. Os sintomas foram verificados visualmente, e o distúrbio foi classificado dependendo do ponto de ocorrência no fruto, de acordo com a classificação proposta por Schaffer (1994). Os resultados foram expressos em percentagem em relação ao número total de frutos analisados.

Sólidos Solúveis (SS): foi determinado por refratometria, utilizando-se um refratômetro digital, modelo PR - 100 Palette (Atago Co, LTD., Japão), conforme normas da Association of Official Analytical Chemists AOAC (1992), e os conteúdos expressos em percentagem.

Acidez Total Titulável (ATT): foi determinada através da técnica recomendada por Kramer (1973), titulando-se $1 \mathrm{~mL}$ de suco diluído em $9 \mathrm{~mL}$ de água destilada, com $\mathrm{NaOH}$ a $0,1 \mathrm{~N}$; e os valores obtidos foram expressos em mmol $\left(\mathrm{H}^{+}\right) / 100 \mathrm{~mL}$.

SSIATT: a relação foi determinada pelo quociente entre as duas características.

Açúcares Solúveis Totais (AST): foram determinados através do método da antrona (Disches, 1962). Partiu-se de uma porção de $100 \mathrm{mg}$ de polpa liofilizada, diluída para $100 \mathrm{~mL}$ com água destilada, e 
desta, tomou-se uma alíquota de $2 \mathrm{~mL}$, que foi diluída para $50 \mathrm{~mL}$ e do qual se utilizou $1,0 \mathrm{~mL}$ para 0 doseamento. Os resultados foram expressos em g $100 \mathrm{~g}^{-1}$ de peso da matéria fresca.

Cálcio Total: utilizaram-se $100 \mathrm{mg}$ de polpa liofilizada, que após digestão nitroperclórica, permitiu o doseamento por espectrofotometria de absorção atômica, conforme metodologia estabelecida por Sarruge \& Haag (1974). Os resultados foram expressos em mmol de $\mathrm{Ca}^{2+} /$ $100 \mathrm{~g}$ de peso da polpa liofilizada.

A análise estatística dos resultados foi feita usando-se o "software" SPSSPC para a verificação das hipóteses de normalidade, homogeneidade e aditividade. Em seguida, o teste de Tukey a $5 \%$ foi aplicado através do Software ESTAT, permitindo comparar as concentrações de $\mathrm{CaCl}_{2}$ testadas e o teste de Dunnett, para se comparar com o controle.

\section{RESULTADOS E DISCUSSÃO}

Foi observada interação significativa entre concentração de $\mathrm{CaCl}_{2}$ e número de aplicação, apenas em relação a textura e acidez total titulável nos frutos analisados após armazenamento refrigerado por 30 dias. Isto indica que o número de aplicações de cálcio se comportou diferentemente dentro de cada concentração de $\mathrm{CaCl}_{2}$ utilizada, nestas variáveis.

As pulverizações foliares e dirigidas para os frutos com $\mathrm{CaCl}_{2}$ nas concentrações testadas não resultaram em incremento desse nutriente nos frutos (TABELA 1), concordando com McKenzie (1995) e Rabelo et al. (1996), porém, contrário ao comportamento observado por Bissoli Jr. (1992), que utilizando concentrações superiores de $\mathrm{CaCl}_{2}(4 \%)$, aumentou o teor do nutriente na polpa dos frutos. Os valores encontrados variaram de 17,978 469 a 20,469 $\mathrm{mmol}$ de $\mathrm{Ca}^{2+} / 100 \mathrm{~g}$ de peso do material liofilizado (TABELA 1). Com relação aos números de aplicações de $\mathrm{CaCl}_{2}$ em précolheita, também não se observou diferença significativa, cujo o teor variaram de 19,016 a 20,726 mmol de $\mathrm{Ca}^{2+} / 100 \mathrm{~g}$ de peso do material liofilizado (TABELA 2).

Provavelmente as concentrações utilizadas foram insuficientes para que houvesse manifestação do efeito do cálcio, podendo ainda esse fato ser atribuído à metodologia de aplicação, não sendo satisfatória a absorção do produto pelos frutos. Deve-se também considerar que o cálcio é um nutriente de pouca mobilidade nos tecidos vegetais.

Maior textura foi observada quando se fizeram duas aplicações de $\mathrm{CaCl}_{2}$ na concentração de $1 \%(61,417 \mathrm{~N})$, e de três ou quatro aplicações na concentração de $2 \%(53,990 \mathrm{~N}$ e 59,573N). (TABELA 3). Por outro lado, quando analisaramse separadamente as concentrações de $\mathrm{CaCl}_{2}$ e comparouse com o tratamento testemunha, não se constatou diferença significativa entre elas (TABELA 3). Apesar de existir uma tendência em associar-se um aumento na firmeza com um aumento no teor de cálcio no fruto (Gerasopoulos et al., 1996), isso não foi constatado nesse trabalho, contradizendo alguns pesquisadores, como Singh, et al. (1993).
Houve o surgimento de manchas de lenticelas em alguns frutos, principalmente nos que foram tratados com $2 \% \mathrm{CaCl}_{2}$, podendo terem sido causadas devido a aplicação de cálcio.

Para SS e açúcares totais, não foi observado efeito da concentração de $\mathrm{CaCl}_{2}$ (TABELA 4). Porém, quando se fez a comparação das concentraçõPes testadas com a testemunha, a diferença significativa foi observada apenas para açúcares solúveis totais, nos frutos analisados após 30 dias de armazenamento, onde as concentrações de $1 \%$ e $2 \%$ diferiram do tratamento

TABELA 1 - Teores de Cálcio Total de manga 'Tommy Atkins' tratada com diferentes concentrações de $\mathrm{CaCl}_{2}$ em pré-colheita. ESAM, Mossoró-RN, 1998.

\begin{tabular}{cc}
\hline Concentrações de $\mathrm{CaCl}_{2}$ & Cálcio Total $^{1 /}$ \\
\hline$\%$ & $\begin{array}{r}\mu \mathrm{mol} \mathrm{de} \mathrm{ca}^{2+} / 100 \mathrm{~g} \text { de peso } \\
\text { do material liofilizado }\end{array}$ \\
0 & $17,97 \mathrm{NS}$ \\
1 & 20,46 aNS \\
2 & 19,51 aNS \\
\hline
\end{tabular}

${ }^{1 /}$ Médias seguidas pela mesma letra nas colunas não diferem significativamente, pelo teste $\mathrm{F}$.

NS/ Não significância pelo teste de Dunnett.

TABELA 2 - Teores de Cálcio Total de manga 'Tommy Atkins' tratada com diferentes números de aplicações de $\mathrm{CaCl}_{2}$ em pré-colheita. ESAM, Mossoró-RN, 1998.

\begin{tabular}{cc}
\hline $\mathrm{N}^{\text {os }}$ de Aplicações de $\mathrm{CaCl}_{2}$ & Cálcio Total $^{2 /}$ \\
\hline $\begin{array}{c}\mu \mathrm{mol} \mathrm{de} \mathrm{Ca}^{2+} / 100 \mathrm{~g} \mathrm{de} \\
\text { peso de material liofilizado }\end{array}$ \\
2 & $20,72 \mathrm{a}$ \\
3 & $20,23 \mathrm{a}$ \\
4 & $19,01 \mathrm{a}$
\end{tabular}

${ }^{2 /}$ Médias seguidas pela mesma letra nas colunas não diferem significativamente, pelo teste de Tukey $(p<0,05)$.

TABELA 3 - Firmeza da polpa (N) de manga 'Tommy Atkins' tratada com $\mathrm{CaCl}_{2}$ em pré-colheita e submetida ao armazenamento refrigerado por 30 dias. ESAM, Mossoró-RN, 1998.

\begin{tabular}{ccc}
\hline $\begin{array}{c}\text { Concentrações } \\
\text { de } \mathrm{CaCl}_{2}\end{array}$ & $\begin{array}{c}\text { Nos de } \\
\text { Aplicações de } \\
\mathrm{CaCl}_{2}\end{array}$ & Textura (N) ${ }^{3 /}$ \\
\hline$\%$ & 0 & \multicolumn{2}{c}{$62,275 \mathrm{NS}$} \\
0 & 2 & $61,417 \mathrm{a}$ \\
\hline 1 & 3 & $42,256 \mathrm{~b} \quad 54,040 \mathrm{NS}$ \\
1 & 4 & $47,743 \mathrm{~b}$ \\
2 & 2 & $44,444 \mathrm{~b}$ \\
2 & 3 & $53,990 \mathrm{a} 52,670 \mathrm{NS}$ \\
\hline 2 & 4 & $59,573 \mathrm{a}$ \\
\hline
\end{tabular}

${ }^{3 /}$ Médias seguidas pela mesma letra na primeira coluna não diferem significativamente, pelo teste de Tukey ( $p \leq 0.05)$, e na segunda coluna, pelo teste de Dunnett.

NS/ Não significância pelo teste de Dunnett. 
testemunha (TABELA 4). Para o número de aplicações de $\mathrm{CaCl}_{2}$, observou-se diferença para SS após 30 dias, e para açúcares totais, após a colheita (TABELA 5). Maiores valores de SS foram obtidos após 30 dias, e maiores valores de açúcares solúveis totais foram obtidos após a colheita.

O teor de SS ideal para manga varia entre 10\% (Medlicott et al.,1988) e 13\%, podendo chegar até 18,5\% ou mais (Corrêa, 1992). Os teores de SS por ocasião da colheita para manga 'Tommy Atkins' visando a exportação, deve variar entre 7\% e 8\% (Sañudo et al., 1997), estando portanto, compatíveis aos valores encontrados no presente trabalho, que foram entre $7,32 \%$ e $7,97 \%$. Conforme a finalidade ou o mercado-alvo, é mais desejável um teor elevado de SS, se for para fins industriais e para o mercado interno de consumo in natura. Porém, ao se considerar o mercado externo, dar-se-á preferência a teores menores de SS, devido ao sabor menos adocicado (Moraes, 1988).

Em relação aos açucares solúveis totais, os valores encontrados foram de 3,38 a 4,53 g $100 \mathrm{~g}^{-1}$ de peso da matéria fresca após a colheita, e de 9,10 a $10,09 \mathrm{~g} 100 \mathrm{~g}^{-1}$ de peso da matéria fresca, após 30 dias (TABELAS 4 e 5). Esses valores estão coerentes com os resultados obtidos por Lima (1997), que também observou o aumento nos teores de açúcares durante o armazenamento de manga.

Para ATT e relação SS/ATT, não foram observados efeitos da concentração de $\mathrm{CaCl}_{2}$, nem do número de aplicações (TABELAS 6, 7, 9 e 10). Mesmo quando compararam-se as concentrações de $\mathrm{CaCl}_{2} \mathrm{com}$ o tratamento testemunha, também não se observou diferença significativa (TABELAS 6 e 9).

Os valores de ATT encontrados, variaram de 15,94 a $18,19 \mathrm{mmolH}^{+} / 100 \mathrm{~mL}$ de suco nos frutos analisados após a colheita, e de 8,15 a $11,06 \mathrm{mmolH}^{+} / 100 \mathrm{~mL}$ de suco, após 30 dias, concordando com os valores encontrados por Trevizaneli (1990) e Bissoli Jr. (1992). Entretanto, nos frutos analisados após 30 dias, houve diferença entre o número de aplicações de $\mathrm{CaCl}_{2}$ dentro da concentração de $2 \%$, onde 0 maior valor de ATT foi registrado quando realizaram-se duas aplicações. Porém, quando se contrastaram as concentrações de $\mathrm{CaCl}_{2}$ com o controle, não se observou diferença significativa (TABELA 8).

Não se observou uma associação entre o tratamento pré-colheita com $\mathrm{CaCl}_{2}$ e a incidência de colapso interno, não observando também, influência das concentrações nem dos números de aplicações de $\mathrm{CaCl}_{2}$, em termos percentuais (\%). Para os frutos analisados logo após a colheita, a incidência variou de 0 a $16 \%$, e de 0 a $13,33 \%$ nos frutos após armazenamento refrigerado por 30 dias (TABELA 11).

É importante considerar os tipos de colapso interno encontrados na pesquisa. Basicamente, o colapso manifestou-se nas formas de tecido esponjoso - 48\%, amolecimento da polpa - $27 \%$ e escurecimento da polpa próximo ao caroço - $25 \%$. Alguns frutos, inclusive, apresentaram dois tipos de manifestação (tecido esponjoso e escurecimento da polpa próximo ao caroço).

TABELA 4 - Sólidos Solúveis e Açúcares Solúveis Totais manga 'Tommy Atkins' tratada com CaCl ${ }_{2}$ em pré-colheita. ESAM, Mossoró-RN, 1998.

\begin{tabular}{|c|c|c|c|c|}
\hline \multirow{2}{*}{$\begin{array}{c}\text { Concentrações de } \\
\mathrm{CaCl}_{2}\end{array}$} & \multicolumn{2}{|c|}{ SS } & \multicolumn{2}{|c|}{ Açúcares Solúveis Totais" } \\
\hline & Após a Colheita & Após 30 dias & Após a Colheita & Após 30 dias \\
\hline$\%$ & \multicolumn{2}{|c|}{ 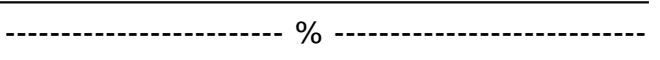 } & \multicolumn{2}{|c|}{ g $100^{-1}$ de peso da matéria fresca } \\
\hline 0 & $7,46 \mathrm{NS}$ & $13,20 \mathrm{NS}$ & $3,77 \mathrm{NS}$ & 8,10 \\
\hline 1 & 7,84 aNS & 13,93 aNS & 3,64 aNS & $9,50 a^{*}$ \\
\hline 2 & 7,52 aNS & 14,00 aNS & 4,21 aNS & $9,86 \mathrm{a}^{*}$ \\
\hline
\end{tabular}

${ }^{4 /}$ Médias seguidas pela mesma letra nas colunas não diferem significativamente, pelo teste $\mathrm{F}$.

NS/ Não significância pelo teste de Dunnett.

*/ Significa que o tratamento diferiu do tratamento testemunha.

TABELA 5 - Sólidos Solúveis e Açúcares Solúveis Totais de manga 'Tommy Atkins' tratada com CaCl. ESAM, Mossoró-RN, 1998.

\begin{tabular}{|c|c|c|c|c|}
\hline \multirow{2}{*}{$\begin{array}{c}\mathrm{N}^{\text {os }} \text { de Aplicações de } \\
\mathrm{CaCl}_{2}\end{array}$} & \multicolumn{2}{|c|}{ SS } & \multicolumn{2}{|c|}{ Açúcares Solúveis Totais } \\
\hline & Após a Colheita & Após 30 dias & Após a Colheita & Após 30 dias \\
\hline \multicolumn{3}{|c|}{ - } & \multicolumn{2}{|c|}{ g $100^{-1}$ de peso da matéria fresca } \\
\hline 2 & 7,32 a & $13,40 \mathrm{~b}$ & $3,86 \mathrm{ab}$ & $9,10 \mathrm{a}$ \\
\hline 3 & 7,97 a & $13,40 \mathrm{~b}$ & $3,38 \mathrm{~b}$ & 9,85 a \\
\hline 4 & $7,75 \mathrm{a}$ & $15,10 \mathrm{a}$ & $4,53 \mathrm{a}$ & 10,09 a \\
\hline
\end{tabular}

5/ Médias seguidas pela mesma letra nas colunas não diferem significativamente, pelo teste de Tukey $(p<0,05)$. 
TABELA 6 - Acidez Total Titulável de manga 'Tommy Atkins' tratada com $\mathrm{CaCl}_{2}$ em pré-colheita, e analisada logo após a colheita. ESAM, Mossoró-RN, 1998.

\begin{tabular}{cc}
\hline Concentrações de $\mathrm{CaCl}_{2}$ & Acidez Total Titulável ${ }^{6 /}$ \\
\hline$\%$ & $\mathrm{mmol} \mathrm{H}^{+} / 100 \mathrm{~mL}$ de suco \\
0 & $15,94 \mathrm{NS}$ \\
1 & $16,86 \mathrm{aNS}$ \\
2 & 17,61 aNS \\
\hline
\end{tabular}

${ }^{6 /}$ Médias seguidas pela mesma letra nas colunas não diferem significativamente, pelo teste $\mathrm{F}$.

NS/ Não significância pelo teste de Dunnett.

TABELA 7 - Acidez Total Titulável de manga 'Tommy Atkins' tratada com $\mathrm{CaCl}_{2}$ em pré-colheita e analisada logo após a colheita. ESAM, Mossoró-RN, 1998.

\begin{tabular}{cc}
\hline Nos de Aplicações de $\mathrm{CaCl}_{2}$ & Acidez Total Titulável $^{7 /}$ \\
\hline 1 & $\mathrm{mmol} \mathrm{H}^{+} / 100 \mathrm{~mL}$ de suco \\
2 & $18,19 \mathrm{a}$ \\
4 & $16,19 \mathrm{a}$ \\
\end{tabular}

${ }^{7 / M e ́ d i a s ~ s e g u i d a s ~ p e l a ~ m e s m a ~ l e t r a ~ n a s ~ c o l u n a s ~ n a ̃ o ~ d i f e r e m ~}$ significativamente, pelo teste de Tukey $(p<0,05)$.

TABELA 8 - Acidez Total Titulável de manga 'Tommy Atkins' tratada com $\mathrm{CaCl}_{2}$ em pré-colheita e submetida ao armazenamento refrigerado por 30 dias. ESAM, Mossoró-RN, 1998.

\begin{tabular}{|c|c|c|c|}
\hline $\begin{array}{l}\text { Concentrações } \\
\text { de } \mathrm{CaCl}_{2}\end{array}$ & $\begin{array}{c}\text { Nos de } \\
\text { Aplicações } \\
\text { de } \mathrm{CaCl}_{2}\end{array}$ & \multicolumn{2}{|c|}{ Acidez Total Titulável ${ }^{8 /}$} \\
\hline$\%$ & & \multicolumn{2}{|c|}{$\mathrm{mmol} \mathrm{H}+/ 100 \mathrm{~mL}$ de suco } \\
\hline 0 & 0 & & $8,700 \mathrm{NS}$ \\
\hline 1 & 2 & 9,752 a & \\
\hline 1 & 3 & $11,534 \mathrm{a}$ & 11,065 aNS \\
\hline 1 & 4 & 11,909 a & \\
\hline 2 & 2 & $9,565 \mathrm{a}$ & \\
\hline 2 & 3 & $6,094 \mathrm{~b}$ & 8,157 aNS \\
\hline 2 & 4 & $8,814 \mathrm{~b}$ & \\
\hline
\end{tabular}

${ }^{8}$ Médias seguidas pela mesma letra na primeira coluna não diferem significativamente, pelo $\mathrm{F}$.

NS/ Não significância pelo teste de Dunnett.

Em um estudo sobre a incidência de colapso interno em diferentes variedades de manga em Jaboticabal - SP, constatou-se que manga 'Tommy Atkins' é uma das mais susceptíveis ao distúrbio, apresentando $100 \%$ dos frutos com obstrução do pedúnculo, com $90 \%$ de sintomas severos, com dados semelhantes para desintegração da polpa (Ferreira et al., 1989).

Apesar da verificação de alguns frutos injuriados pelos sintomas de colapso interno, não se observou, no geral, uma grande incidência, já que apenas 17 frutos apresentaram o distúrbio, representando $6,07 \%$ do total de
TABELA 9 - Relação SS/ATT de manga 'Tommy Atkins' tratada com diferentes concentrações de $\mathrm{CaCl}_{2} \mathrm{em}$ pré-colheita. ESAM, Mossoró-RN, 1998.

\begin{tabular}{ccc}
\hline \multirow{2}{*}{$\begin{array}{c}\text { Concentrações } \\
\text { de } \mathrm{CaCl}_{2}\end{array}$} & \multicolumn{2}{c}{ SS/ATT// } \\
\cline { 2 - 3 } & Após a colheita & Após 30 dias \\
\hline$\%$ & $0,470 \mathrm{a}$ & $1,524 \mathrm{NS}$ \\
0 & $0,479 \mathrm{a}$ & 1,284 aNS \\
2 & $0,435 \mathrm{a}$ & 1,876 aNS \\
\hline
\end{tabular}

9/Médias seguidas pela mesma letra nas colunas não diferem significativamente, pelo teste de $\mathrm{F}$.

NS/ Não significância pelo teste de Dunnett.

TABELA 10 - Relação SS/ATT de manga 'Tommy Atkins' tratada com $\mathrm{CaCl}_{2}$ em pré-colheita. ESAM, Mossoró-RN, 1998.

\begin{tabular}{ccc}
\multirow{2}{*}{$\begin{array}{c}\text { Nos de Aplicações } \\
\text { de } \mathrm{CaCl}_{2}\end{array}$} & \multicolumn{2}{c}{ SS/ATT10/ } \\
\cline { 2 - 3 } & Após a colheita & Após 30 dias \\
\hline & & \\
3 & $0,418 \mathrm{a}$ & $1,422 \mathrm{a}$ \\
4 & $0,498 \mathrm{a}$ & $1,743 \mathrm{a}$ \\
\hline
\end{tabular}

10/ Médias seguidas pela mesma letra nas colunas não diferem significativamente, pelo teste de Tukey $(p<0,05)$.

TABELA 11 - Incidência de Colapso Interno em manga 'Tommy Atkins'tratada com $\mathrm{CaCl}_{2}$ em précolheita e submetida ao armazenamento refrigerado por 30 dias. ESAM, Mossoró-RN, 1998.

\begin{tabular}{|c|c|c|c|}
\hline \multirow{2}{*}{$\begin{array}{c}\text { Concentrações } \\
\text { de } \mathrm{CaCl}_{2}\end{array}$} & \multirow{2}{*}{$\begin{array}{c}N^{o s} \text { de } \\
\text { Aplicações } \\
\text { de } \mathrm{CaCl}_{2}\end{array}$} & \multicolumn{2}{|c|}{$\begin{array}{c}\text { Incidência de Colapso } \\
\text { Interno }\end{array}$} \\
\hline & & $\begin{array}{l}\text { Após a } \\
\text { Colheita }\end{array}$ & $\begin{array}{c}\text { Após } 30 \\
\text { dias }\end{array}$ \\
\hline$\%$ & & ---------------- & ----------------. \\
\hline \multirow[t]{2}{*}{0} & 0 & 0,00 & 6,66 \\
\hline & 2 & 0,00 & 13,33 \\
\hline \multirow[t]{3}{*}{1} & 3 & 8,00 & 6,66 \\
\hline & 4 & 8,00 & 0,00 \\
\hline & 2 & 0,00 & 6,66 \\
\hline \multirow[t]{2}{*}{2} & 3 & 16,00 & 6,66 \\
\hline & 4 & 8,00 & 6,66 \\
\hline
\end{tabular}

frutos do experimento, sendo portanto, percentual extremamente menor do que o encontrado por Vaz (1990), que foi maior que $50 \%$ do total de frutos colhidos, quando aplicou diferentes doses de N, K, Ca, Zn e B.

Houve também a manifestação do fungo Lassiodiplodia theobromae, principalmente após o armazenamento. A ocorrência desse fungo pode ocorrer tanto na fase de produção como em pós-colheita, causando o apodrecimento dos frutos armazenados, desqualificando-os para comercialização (Schaffer, 1994). 


\section{CONCLUSÕES}

- O tratamento com $\mathrm{CaCl}_{2}$ em pré-colheita da manga não se mostrou eficiente para a absorção do cálcio pelo fruto.

- Não houve resposta das concentrações de $\mathrm{CaCl}_{2}$ testadas em relação as características de qualidade avaliadas, com exceção dos açúcares totais, nos frutos analisados após 30 dias.

- Houve efeito do número de aplicações de $\mathrm{CaCl}_{2}$ sobre o teor de sólidos solúveis (após 30 dias), açúcares solúveis totais (após a colheita) e textura.

- A incidência de colapso interno não foi associada ao tratamento com $\mathrm{CaCl}_{2}$ em pré-colheita.

\section{REFERÊNCIAS BIBLIOGRÁFICAS}

ASSOCIATION OF OFFICIAL ANALYTICAL CHEMISTS. Official methods of analysis of the Association of Official Analytical Chemists. Washington: AOAC, 1992.

BISSOLI JR., W. Qualidade de mangas (Mangifera indica, L. cV. 'Tommy Atkins') sob influência da pulverização pré-colheita dos frutos com cálcio e boro. Lavras, 1992. 86p. Dissertação (Mestrado) - Escola Superior de Agricultura de Lavras.

CORRÊA, G.C. Efeito da época de oferta e classificação, na qualidade de frutos de mangueira (Mangifera indica, L. cv. Tommy Atkins). Lavras, 1992. 80p. Dissertação ( Mestrado) Universidade Federal de Lavras.

DISCHES, Z. Color reactions of carbohydrates. In: WHISTHER, R.L.; WOLFRN, M.L. (Ed.) Methodes in carbohydrates chemistry. New York: Academic Press, 1962. v.1, p.477-512.

FERREIRA, F.R.; VITT, G.C.; DONADIO, L.C. Incidência do colapso interno do fruto em cultivares de manga em Jaboticabal. In: CONGRESSO BRASILEIRO DE FRUTICULTURA, 10., Fortaleza, 1989. Anais. Fortaleza: SBF, 1989. p.328-333.

FERREIRA, R.F. Colapso interno do fruto. In: SIMPÓSIO SOBRE MANGICULTURA, 2., Jaboticabal,1989. Anais. Jaboticabal: UNESP/FCAV, 1989. p.149-155.

GERASOPOULOS, D.; CHOULIARAS, V.; LIONAKIS, S. Effects of preharvest calcium chloride sprays on maturity and storability of Hayward kiwifruit. Postharvest Biology and Technology, v.7, p 65-72, 1996.

KRAMER, A. Fruits and vegetables. In: TWIGG, B.A. Quality control for food industry. Connecticut: AVI Publishing, 1973. v.2, p.157-227.

LIMA, L. C. de O. Tecido esponjoso em manga 'Tommy Atkins': transformações químicas e bioquímicas no mesocarpo durante o amadurecimento. Lavras, 1997. 151p. Tese (Doutorado) - Universidade Federal de Lavras.
McKENZIE, C.B. The effect of calcium and potassium foliar and fruit sprays on Sensation mango leaf nutrient concentration and fruit quality. Yeabook of the South African Mango Growerss Association, v.15, p.24-25, 1995.

MEDLICOTT, A.P.; REYNALDS, S.B.; NEW, S.W; THOMPSON, A.K. Harvest maturity effects on mango fruit ripening. Tropical Agriculture, v.65, p.153-157, 1988.

MENEZES, J.B. Colapso interno em manga : um problema sério de qualidade pós-colheita. Informativo da Sociedade Brasileira de Fruticultura, v.16, p.10-11, 1997.

MORAES, D.M. de. Desenvolvimento e maturação pós-colheita de frutos de manga (Mangifera indica, L.) cv. 'Ubá'. Viçosa, 1988. 36p. Dissertação (Mestrado) - Universidade Federal de Viçosa.

RABELO, J.E.S.; SILVA, M.M.; GASPAR, J.W.; COUTO, F.A.A. Efeito da aplicação foliar de cloreto de cálcio e ácido bórico sobre o "colapso interno" da manga "Tommy Atkins". In: SÃO JOSÉ, A.R.; SOUZA, I.V.B.; MARTINS FILHO, J.; MORAIS, O.M. (Coord.) Manga: tecnologia de produção e mercado. Vitória da Conquista: DFZ/UESB, 1996. p.136-138.

SAÑUDO, R.; BUSTILLOS, R.J.A.; GARCIA, L.P. de; MOLINA, E.B.; NUÑO, S.O.; ANGEL, D.N. Manejo postcosecha del mango. México: EMEX, 1997.

SARRUGE, J.R.; HAAG, H.P. Análise química em plantas. Piracicaba: USP/ESALQ, Departamento de Química, 1974. $56 \mathrm{p}$.

SCHAFFER, B. Mango disorders caused by abiotic factors. In: PLOETZ, R.C.; ZENTHYER, G.A.; NISHIJIMA, W.T.; ROHRBACH, K.G.; OHR, H.D. Compedium of Fruit Disorders. Minesota: APS Press, 1994. p.43-44.

SINGH, B.P.; TANDON, D.K.; KALRA, S.K. Changes in postharvest quality of mangoes affected by preharvest application of calcium salts. Scientia Horticulturae, v.54, p.211-219, 1993.

TREVIZANELI, V.L. Influência da adubação na qualidade tecnológica de frutos de manga (Mangifera indica, L.) cv. Tommy Atkins. Jaboticabal, 1990. 75 p. Monografia (Graduação) - Faculdade de Ciências Agrárias e Veterinárias, Universidade Estadual Paulista "Júlio de Mesquita Filho".

VAZ, L.A.A. Efeitos da aplicação de diferentes níveis de $\mathrm{N}, \mathrm{K}$, $\mathrm{Ca}, \mathrm{Zn}$ e B na produção e na ocorrência do colapso interno do fruto em manga do cv. "Tommy Atkins". Jaboticabal, 1990. Monografia (Graduação) - Faculdade de Ciências Agrárias e Veterinárias, Universidade Estadual Paulista "Júlio de Mesquita Filho".

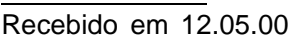

